\title{
Dual Functions of Bacteriophage T4D Gene 28 Product: Structural Component of the Viral Tail Baseplate Central Plug and Cleavage Enzyme for Folyl Polyglutamates
}

\author{
II. Folate Metabolism and Polyglutamate Cleavage Activity of \\ Uninfected and Infected Escherichia coli Cells and Bacteriophage \\ Particles
}

\author{
LLOYD M. KOZLOFF†* AND M. LUTE† \\ Department of Microbiology and Immunology, University of Colorado Health Sciences Center, \\ Denver, Colorado 80262
}

Received 18 July 1980/Accepted 14 July 1981

\begin{abstract}
We investigated the rolo of the T4D bacteriophage gene 28 product in folate metabolism in infected Escherichia coli cells by using antifolate drugs and a newly devised assay for folyl polyglutamate cleavage activity. Preincubation of host $E$. coli cells with various sulfa drugs inhibited phage production by decreasing the burst size when the phage particles produced an altered gene 28 product (i.e., after infection under permissive conditions with T4D $28^{\text {ts }}$ or T4D am28). In addition, we found that another folate analog, pyrimethamine, also inhibited T4D $28^{\text {ts }}$ production and T4D 28am produetion, but this analog did not inhibit wildtype T4D production. A temperature-resistant revertant of T4D $28^{\text {ts }}$ was not sensitive to either sulfa drugs or pyrimethamine. We developed an assay to measure the enzymatic cleavage of folyl polyglutamates. The high-molecularweight folyl polyglutamate substrate was isolated from $E$. coli B cells infected with T4D am28 in the presence of labeled glutamic acid and was characterized as a folate compound containing 12 to 14 labeled glutamate residues. Extracts of uninfected bacteria liberated glutamate residues from this substrate with a $\mathrm{pH}$ optimum of 8,4 to 8,5. Extracts of bacteriophage T4D-infected $E$. coli B cells exhibited an additional new folyl polyglutamate cleavage activity with a $\mathrm{pH}$ optimum of about 6.4 to 6.5, which was clearly distinguished from the preexisting activity in the uninfected host cells. This new activity was induced in $E$. coli B cells by infection with wild-type T4D and T4D amber mutants $29^{-}, 26^{-}, 27^{-}, 51^{-}$, and $10^{-}$, but it was not induced under nonpermissive conditions by T4D am28 or by T4D $28^{\text {ts }}$. Mutations in gene 28 affected the properties of the induced cleavage enzyme. Wild-type T4D-induced cleavage activity was not inhibited by pyrimethamine, whereas the T4D $28^{\text {ts }}$ activity induced at a permissive temperature was inhibited by this folate analog. Folyl polyglutamate cleavage activity characteristic of the activity induced in host cells by wild-type T4D or by T4D gene 28 mutants was also found in highly purified preparations of these phage ghost particles. The T4D-induced cleavage activity could be inhibited by antiserum prepared against highly purified phage baseplates. We concluded that T4D infection induced the formation of a new folyl polyglutamate cleavage enzyme and that this enzyme was coded for by T4D gene 28. Furthermore, since this gene product was baseplate tail plug component which had both its antigenic sites and its catalytic sites exposed on the phage particle, it was apparent that this enzyme formed part of the distal surface of the phage baseplate central tail plug.
\end{abstract}

In the accompanying paper (17) Kozloff and Zorzopulos present evidence that the product of T4D bacteriophage gene 28 is a protein which plays a structural role in forming the central

† Present address: Department of Microbiology, University of California, San Francisco, CA 94143. plug of the tail baseplate of the phage particle. Previous work $(12,13,20)$ indicated that the gene 28 product plays a catalytic role in cleaving very large folyl polyglutamates. When this gene product was defective, these compounds accumulated in infected cells. However, a direct dem- 
onstration of such a catalytic function required the development of an appropriate assay. Previous attempts to assay for this presumed activity in infected cells by using ${ }^{14} \mathrm{C}$-labeled pteroyl heptaglutamate labeled in its terminal glutamate residue were unsuccessful when extracts from uninfected or infected Escherichia coli B cells were used. A highly sensitive assay procedure has now been developed; this procedure uses a biologically prepared high-molecularweight labeled substrate and follows the general principles originally described by Krumdieck and Baugh (18) for measuring such activities.

There have been no reports of the presence in bacteria of enzymes specific for folyl polyglutamates. The report by Volcani and Margolith (22) describing a $\gamma$-L-glutamyl carboxypeptidase clearly showed that this enzyme did not require the presence of a pteridine moiety as an obligatory feature of the substrate. Although characterization of the enzyme activity found in uninfected cells is not complete, it is worth pointing out that this activity does have an alkaline optimum $\mathrm{pH}$ of 8.4 to 8.5 , which is not typical of other $\gamma$-glutamyl carboxypeptidases (3).

The major emphasis in this paper is on folate metabolism and the induction of a new $\gamma$-glutamyl carboxypeptidase induced in cells after infection by bacteriophage T4D. This enzyme clearly does have a catalytic site which does recognize the pteroyl group since a pteroyl antagonist inhibited its activity. We also present evidence that this new activity is coded for by T4D gene 28. When this enzyme is altered and has a decreased efficiency, the production of new phage particles is sensitive to other antifolate agents, such as the sulfa drugs. Finally, using enzymatic cleavage activity as a marker, we found not only that this enzyme is part of the baseplate but also that it has its catalytic site exposed on the distal surface of the central plug of the baseplate.

\section{MATERIALS AND METHODS}

Materials and procedures. The sources and characteristics of most of the bacteriophage and bacterial strains used are described in the accompanying paper (17). We constructed an additional double mutant of T4D, which contained amber mutations in both gene 11 and gene 34, by crossing T4D mutant N93 (gene 11) with B25 (gene 34 ) in the permissive bacterium CR63. Individual plaques were picked and tested for failure to complement either parent $\mathrm{T} 4 \mathrm{D}$ strain on plates where $E$. coli $\mathrm{B}$ was the host. Upon infection of $E$. coli $\mathrm{B}$, this mutant produced particles whose baseplates lacked both the long tail fibers and the gene 11 and gene 12 products. Pyrimethamine [2,4-diamino-5( $p$-chlorophenyl)-6-ethyl pyrimidine; lot 56820] and trimethoprim [2,4-diamino-5-(3,4,5-trimethoxybenzyl)-pyrimidine; lot 55637], which are well-known fo- late analogs and inhibitors of dihydrofolate reductase, were gifts from J. Burchall, Burroughs Wellcome Co.

Preparation of ${ }^{3} \mathrm{H}$-labeled folyl polyglutamate. Labeled substrate was prepared as follows. A 200-ml amount of M9 glucose synthetic medium (1) was supplemented with the following L-amino acids (final concentrations, $20 \mu \mathrm{g} / \mathrm{ml}$ ): Arg, Asp, Trp, Phe, Val, His, Leu, Lys, Gly, Isl, Ser, Pro, Met, Thr, Cys, Tyr, Ala, and Glu. Adenine, guanine, uracil, and thymine, all at $20 \mu \mathrm{g} / \mathrm{ml}$, were also added to this medium. A 5.0$\mathrm{ml}$ subinoculum of $E$. coli B was grown overnight and then added to the main flask, and the bacteria were grown at $30^{\circ} \mathrm{C}$ to a concentration of approximately 3 $\times 10^{8}$ cells per ml. Then 2.0 to $4.5 \mathrm{mCi}$ of $\mathrm{DL}-\left[{ }^{3} \mathrm{H}\right]-$ glutamate (specific activity, $572 \mathrm{mCi} / \mathrm{mmol}$; New England Nuclear Corp.) was added, and the bacterial culture was incubated at $30^{\circ} \mathrm{C}$ for $30 \mathrm{~min}$. T4D am28 (A452) was added so that there were four T4 phage per $E$. coli cell. The culture was shaken for $20 \mathrm{~min}$ and then chilled in ice. The infected cells were centrifuged at $10,000 \mathrm{rpm}$; the packed volume of the pellet was about $0.4 \mathrm{ml}$. Then 5 volumes $(2.0 \mathrm{ml})$ of cold $10 \%$ trichloroacetic acid containing $6.0 \mathrm{M}$ urea and $0.1 \%$ Cleland reagent was added to the pellet. This extraction procedure and the following isolation steps were adapted from the method of Baugh et al. (3). The added trichloroacetic acid-urea solution was used to suspend the packed cells and to transfer the suspension to a chilled glass homogenizer. After homogenization, the material was clarified by centrifugation in the cold at $20,000 \mathrm{rpm}$ in a Spinco centrifuge by using a \#30 rotor. The pellet was extracted with $2.0 \mathrm{ml}$ of $1 \%$ trichloroacetic acid- $0.1 \%$ Cleland reagent. The pellet was discarded, and the supernatant fluids were combined and carefully neutralized to $\mathrm{pH} 7.0$ with 0.1 $\mathrm{N} \mathrm{NaOH}$; usually the supernatants were stored overnight at $-20^{\circ} \mathrm{C}$. Then the frozen solution was thawed and diluted with 5 volumes of $0.1 \%$ Cleland reagent. The diluted cold extract was passed through a small (total volume, $\sim 4.0 \mathrm{ml}$ ) DEAE column in the $\mathrm{Cl}^{-}$form. The column was washed with $3.0 \mathrm{ml}$ of water containing Cleland reagent, and the effluent was discarded. Then $4.0 \mathrm{ml}$ of $0.2 \mathrm{M} \mathrm{NaCl}$ and $4.0 \mathrm{ml}$ of $0.4 \mathrm{M} \mathrm{NaCl}$ (both containing Cleland reagent and $0.005 \mathrm{M}$ phosphate buffer, pH 7.0) were passed through the column. These salt solutions, which eluted the folates containing six or fewer glutamate residues, were collected separately. After an additional wash with $4.0 \mathrm{ml}$ of $0.005 \mathrm{M}$ phosphate (pH 7.0), the high-molecularweight folates containing 12 or more folate residues were eluted with $6.0 \mathrm{ml}$ of $0.5 \mathrm{~N} \mathrm{HCl}$ containing Cleland reagent. The $\mathrm{HCl}$ eluates gave a single sharp peak of ${ }^{3} \mathrm{H}$ radioactivity when they were collected in three portions of $2.0 \mathrm{ml}$ each. The first $2.0-\mathrm{ml} \mathrm{HCl}$ eluate contained about $20 \%$ of the radioactivity, the second $2.0 \mathrm{ml}$ contained $65 \%$, and the third $2.0 \mathrm{ml}$ contained about $15 \%$. Only the tube containing the second eluate was used as a substrate in subsequent experiments. This solution was neutralized carefully to $\mathrm{pH} 7.0$ and was stored at $-20^{\circ} \mathrm{C}$. Usually, the yield was about $1 \mathrm{nmol}$ of folate per $200 \mathrm{ml}$ of original infected culture.

The radioactive substrate was characterized as a high-molecular-weight polyglutamate form of folate in several ways in addition to its chromatographic be- 
havior. In one preparation ${ }^{14} \mathrm{C}$-labeled $p$-aminobenzoic acid (about $150 \mu \mathrm{Ci}$; ICN) (12) was added to the original bacterial growth medium in addition to the $\left[{ }^{3} \mathrm{H}\right]$ glutamic acid added just before infection. The ratio of $\left[{ }^{3} \mathrm{H}\right]$ glutamate to ${ }^{14} \mathrm{C}$-labeled $p$-aminobenzoic acid in the various fractions obtained during the isolation of the folate compounds was determined. The highest ratio was found in the second $2.0 \mathrm{ml}$ of $0.5 \mathrm{~N}$ $\mathrm{HCl}$ used to elute the folate from the column. This eluate had 25 times the radioactivity ratio of glutamate to $p$-aminobenzoic acid of low-molecular-weight folates eluting with $0.2 \mathrm{M} \mathrm{NaCl}$ and 4 times the ratio of glutamate to $p$-aminobenzoic acid of the folates eluting with $0.4 \mathrm{M} \mathrm{NaCl}$. Since T4D $28^{-}$phage infection caused the accumulation of a high-molecular-weight folate, this pattern of relative radioactivities was as expected. All of the tritium radioactivity (more than 95\%) was readily adsorbed by activated charcoal (see below), but after treatment with purified hog kidney conjugase (9) (an exopeptidase specific for the $\gamma$-glytamyl bonds of folyl polyglutamates) all (more than 98\%) of the $\left[{ }^{3} \mathrm{H}\right]$ glutamate was no longer adsorbable by charcoal. The amount of radioactive high-molecular-weight folate isolated was measured by using the fluorometric procedure of Allfrey et al. (2). This analytical procedure gave the values expected from both the specific activity of the $\left[{ }^{3} \mathrm{H}\right]$ glutamate and the amount of high-molecular-weight folates accumulating in T4D $28^{-}$-infected cells. Based on these criteria, we concluded that we had a preparation of pteroyl glu $_{12-14}$ labeled with $\left[{ }^{3} \mathrm{H}\right]$ glutamate. However, it should be emphasized that the final substrate preparations obtained by this procedure had quite low concentrations of folate, which varied from $2 \times 10^{-7}$ to $8 \times 10^{-7}$ $\mathbf{M}$ in different preparations.

Other compounds were furnished by C. M. Baugh as folyl polyglutamyl substrates (3). These were pteglu $_{3}$ and pteglu $\mathrm{u}_{7}$, which contained ${ }^{14} \mathrm{C}$ in their C-terminal glutamate residues.

Enzymatic assay for cleavage of high-molecular-weight labeled folyl polyglutamate. The procedure of Krumdieck and Baugh $(4,18)$ was modified to assay for enzymatic activity which cleaved the folate polyglutamates. In the original procedure, an unreacted substrate containing labeled glutamate residues was adsorbed by activated charcoal in strongly acidic solutions, leaving free monoglutamate residues in the supernatant fluid. However, Silink et al. (21) have pointed out that if a $\gamma$-glutamyl peptidase acts as an endopeptidase, then the freed oligoglutamyl peptides bind to the charcoal, particularly at low $\mathrm{pH}$ values. Therefore, we modified the assay in the following ways: the unreacted substrate was adsorbed to charcoal at $\mathrm{pH} 3.2$ rather than at $\mathrm{pH} 2.0$; the adsorption mixture was diluted with water to decrease the relative concentration of the released glutamyl peptides and thus decrease nonspecific binding to the charcoal; and bovine serum albumin was added to improve the packing of the charcoal.

The standard assay mixture used, which was developed to conserve substrates, contained $10 \mu \mathrm{l}$ of folyl polyglutamate substrate (usually $8 \times 10^{-7} \mathrm{M}$ for the folate residue; 300 to $900 \mathrm{cpm}$ ), $5 \mu \mathrm{l}$ of $10^{-3} \mathrm{M}$ glutamate in buffer, $30 \mu \mathrm{l}$ of additional buffer, and up to 30 $\mu l$ of enzyme preparation containing 20 to $50 \mu \mathrm{g}$ of protein. Usually, this mixture $(75 \mu \mathrm{l})$ was incubated in stoppered tubes at $35^{\circ} \mathrm{C}$ for $1 \mathrm{~h}$ or more. The reaction was terminated by adding, in order, $25 \mu$ l of cold $10 \%$ trichloroacetic acid, $20 \mu$ l of $0.05 \%$ bovine serum albumin in water, $50 \mu \mathrm{l}$ of $0.4 \mathrm{M}$ sodium acetate and 50 $\mu$ l of a $0.5 \%$ Norite A suspension in $0.1 \mathrm{M}$ acetate $(\mathrm{pH}$ 3.0). The final volume was $400 \mu \mathrm{l}$, and the final $\mathrm{pH}$ was 3.2. We also included a substrate blank, in which the substrate was incubated in buffer; the enzyme was only added after $10 \%$ trichloroacetic acid was added. The charcoal precipitate was centrifuged at $1,500 \mathrm{rpm}$ for $10 \mathrm{~min}$, and the resulting supernatant was removed. A measured amount (usually $300 \mu \mathrm{l}$ ) was added to a scintillation vial containing $10 \mathrm{ml}$ of Aquasol (New England Nuclear Corp.). The radioactivity was measured by counting in a Beckman ambient scintillation counter for a minimum of 2,000 counts over background. It was possible to measure reasonably accurately the cleavage of as little as 2 to $3 \%$ of the total of 8 pmol of substrate. Usually, the enzyme reaction was incubated until at least 0.5 to $1.0 \mathrm{pmol}$ was cleaved.

The protein concentration was determined fluorometrically with an Amino-Bowman spectrophotofluorometer; a solution containing equal amounts of serum albumin, ovalbumin, and $\gamma$-globulin was used as a standard. Typically, when a solution in a $150-\mu l$ cuvette containing $500 \mu \mathrm{g}$ of total protein per ml was exited at $280 \mathrm{~nm}$, the emitted light at $340 \mathrm{~nm}$ gave a fluorescence reading of 1.2 .

\section{RESULTS}

Involvement of T4D gene 28 product in folate metabolism. The well-known effects of various sulfa drugs in preventing folate synthesis in gram-negative bacteria suggested that these drugs might differentially affect phage formation in cells in which folate metabolism is disturbed. It has been shown that cells infected with phage which produce little or no active gene 28 product accumulate large folyl polyglutamates (20). Figure 1 shows that three sulfa drugs (sulfadiazine, sulfathiazole, and sulfanilamide) all inhibited the formation of plaques by T4D $28^{\text {ts }}$ at $25^{\circ} \mathrm{C}$ but had no effect on plaque formation by wildtype T4D phage at the concentrations and temperature tested. It should be noted that sulfadiazine was more effective than sulfathiazole, whereas even at the highest concentration used, sulfanilamide was the least effective in inhibiting T4D $28^{\text {ts }}$. We also examined the effects of sulfadiazine on the plating efficiencies of other T4D phage mutants. We found that when T4D am28 was plated on permissive strain $\mathrm{CR} 63$ at $37^{\circ} \mathrm{C}$, it was extremely sensitive to $1 \mathrm{mM}$ sulfadiazine (plating efficiency, less than 0.1 ). On the other hand, when wild-type T4D and T4D amber mutants in genes $5,6,7,8,9,10,11,12,14,15,18$, $23,26,34,35,36,37,38,48,51$, and 54 were plated on strain CR63 in the presence of $1 \mathrm{mM}$ sulfadiazine, they gave normal plating efficiencies (i.e., 1.0). T4D am29 was somewhat sensitive 


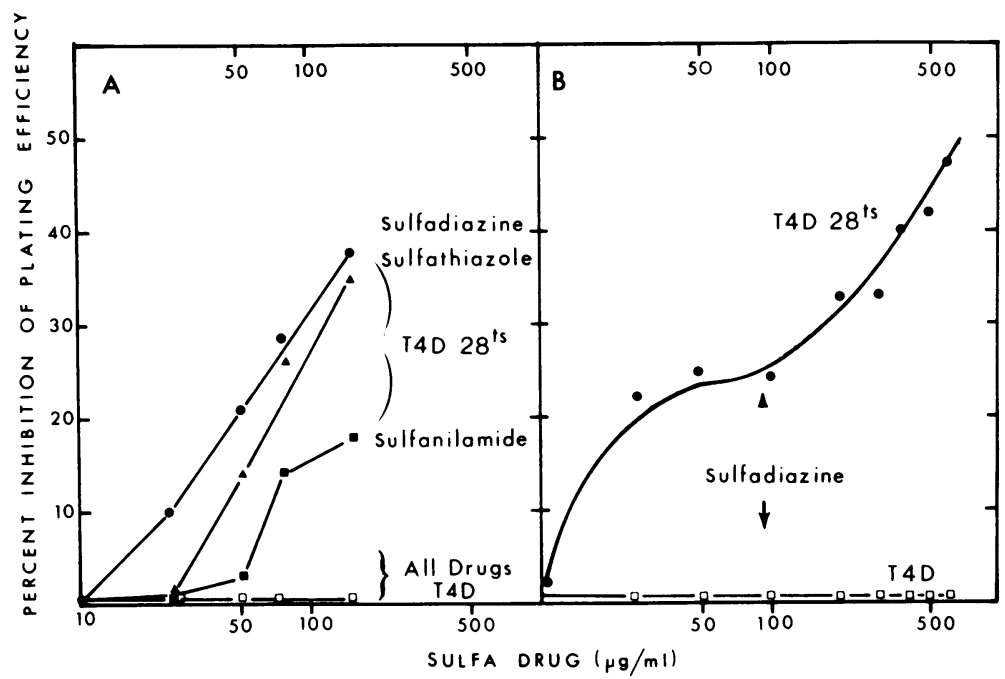

FIG. 1. Effects of various sulfa drugs on the plating efficiencies of T4D and T4D $28^{t s}$. E. coli B cells were grown in broth, washed, suspended in saline, and plated with T4D or T4D $28^{\text {ts }}$ by the standard pour method on the synthetic medium (containing uracil) used for $E$. coli strain OK305; varying concentrations of different sulfa drugs were added to both the base layer and the overlay. Two separate experiments were performed with sulfadiazine. (A) Maximum concentration of sulfadiazine used was $150 \mu \mathrm{g} / \mathrm{ml}$. (B) Maximum sulfadiazine concentration used was $500 \mu \mathrm{g} / \mathrm{ml}$.

to $1 \mathrm{mM}$ sulfadiazine but was more resistant than T4D am28; this mutant gave plating efficiencies of 0.1 to 0.2 . It should be noted that the virus-induced cleavage activity in extracts of $E$. coli $\mathrm{B}$ infected with T4D am29 was less than the cleavage activity in cells infected with wild-type T4D (see below). The sensitivity of T4D am29 to sulfadiazine implied that the gene 29 product may also be involved in some way with folate metabolism.

We investigated the mechanism of sulfa drug inhibition of T4D $28^{\text {ts }}$ plaque formation by using sulfadiazine to inhibit phage growth in liquid cultures. E. coli B was grown in OK305 medium containing uracil, and sulfadiazine was added at different times before and after infection with either T4D or T4D $28^{\text {ts }}$ under conditions of onestep growth at $28^{\circ} \mathrm{C}$. The latent period and the burst size could be determined in these experiments (1). The presence of $400 \mu \mathrm{g}$ of sulfadiazine per ml had no effect on the latent period or burst size of either T4D or T4D $28^{\text {ts }}$ when the drug was added $15 \mathrm{~min}$ before infection, at the time of infection, or $15 \mathrm{~min}$ after infection. However, when sulfadiazine was added to a bacterial culture $3 \mathrm{~h}$ before infection, there was a pronounced effect on T4D $28^{\text {ts }}$ phage growth but not on wildtype T4D phage growth. For instance, although the latent period remained the same $(40 \mathrm{~min})$ with T4D $28^{\text {ts }}$, the burst size decreased from 150 to 60 phage per cell; after $5 \mathrm{~h}$ of preincubation with $400 \mu \mathrm{g}$ of sulfadiazine per $\mathrm{ml}$, the burst size decreased to less than 1 particle per cell. On the other hand, T4D grew as well on cells incubated with $400 \mu \mathrm{g}$ of sulfadiazine per $\mathrm{ml}$ for $3 \mathrm{~h}$ before infection as it did in the absence of sulfadiazine. There was no increase in the latent period, and the burst size was 270 phage per cell, which was the same value obtained in the absence of sulfadiazine. Furthermore, there was measurable T4D phage growth (burst size, 25 phage per cell) with bacteria preincubated for $5 \mathrm{~h}$ with sulfadiazine. These results explain the decreases in plating efficiency (Fig. 1) with sulfa drugs since on plates the host cells were exposed for long periods before being infected. The simplest interpretation of these results is that during sulfadiazine treatment, while the cells were growing slowly, the concentration of cellular folates was reduced considerably. Subsequently, any infection which also resulted in aberrant folate metabolism, such as an infection with T4D $28^{\text {ts }}$ or T4D 28am, decreased the effective folate concentration and led to reduced phage formation. With pretreatment with $400 \mu \mathrm{g}$ of sulfadiazine per $\mathrm{ml}$ for 3 to $5 \mathrm{~h}$, the primary effect observed inT4D $28^{\text {ts }}$-infected cells was the decrease in the number of phage particles formed, whereas the latent period remained the same. The marked reduction in burst size supported the hypothesis that an essential component for forming phage particles was missing. The most likely missing phage structural component after sulfadiazine pretreatment was the phage baseplate dihydropteroyl hexglutamate.

Effect of pyrimethamine, a folate analog, 
on T4D, T4D 28, and T4D am28. Johnson and Hall (5) showed that at $37^{\circ} \mathrm{C}$ the plating efficiency of wild-type T4D was inhibited greatly by the addition of a variety of folate analogs to the growth medium, especially in the presence of added sulfanilamide. These authors showed that the main effect of these compounds was the inhibition of the virus-induced dihydrofolate reductase. The sulfa drug presumably acted synergistically with dihydrofolate reductase inhibitors by reducing the concentration of intracellular folates. Such a mechanism is usually described as a "sequential blockade." We examined the usual synergistic combination of trimethoprim (a known dihydrofolate reductase inhibitor) plus sulfanilamide for any differential effects on the plating efficiencies of T4D and T4D $28^{\text {ts }}$. In these experiments $E$. coli B strain TRIM 102, an $E$. coli B strain whose dihydrofolate reductase is resistant to trimethoprim $(14,16)$, was used as the host cell. T4D and T4D $28^{\text {ts }}$ were plated onto $\mathrm{OK} 305$ medium containing concentrations of up to $20 \mu \mathrm{g}$ of trimethoprim per ml and $0.45 \mu \mathrm{g}$ of sulfanilamide per $\mathrm{ml}$, and the plates were incubated at $25^{\circ} \mathrm{C}$. We observed no effect on the plating efficiency of either viral strain at this temperature. However, when similar experiments were performed with pyrimethamine (another known folate analog which inhibits dihydrofolate reductase) plus sulfanilamide, we observed a large difference between the plating efficiencies of the two viral strains (Fig. 2). At $25^{\circ} \mathrm{C}$ wild-type T4D plating efficiency was not affected by these two drugs, but the plating efficiency of T4D $28^{\text {ts }}$ was very sensitive, and plaque formation could be inhibited almost completely.

The maximum concentration of sulfanilamide used in these combination experiments $(0.5 \mu \mathrm{g} /$ $\mathrm{ml}$ ) was much lower than the concentration of sulfanilamide used alone $(150 \mu \mathrm{g} / \mathrm{ml})$ (Fig. 1), which produced only about $20 \%$ inhibition of the plating efficiency of T4D $28^{\text {ts }}$. Therefore, we also examined the effect of pyrimethamine alone (Fig. 2), and we found that the plating efficiency of T4D $28^{\text {ts }}$ was quite sensitive to pyrimethamine, whereas the plating efficiency of T4D was not sensitive to this compound at $25^{\circ} \mathrm{C}$. We made extracts of both T4D- and T4D $28^{\text {ts }}$-infected $E$. coli B cells (at $25^{\circ} \mathrm{C}$ ) by using standard procedures and examined the sensitivities of the T4D- and T4D $28^{\text {ts }}$-induced dihydrofolate reductases to pyrimethamine. As expected, we found that T4D- and T4D $28^{\text {ts }}$-induced dihydrofolate reductase activities were identical; they were $50 \%$ inhibited by $0.3 \pm 0.05$ and $0.25 \pm 0.05$ $\mu \mathrm{M}$ pyrimethamine, respectively. Although pyrimethamine is a well-known inhibitor of dihydrofolate reductase, since T4D and T4D $28^{\text {ts }}$

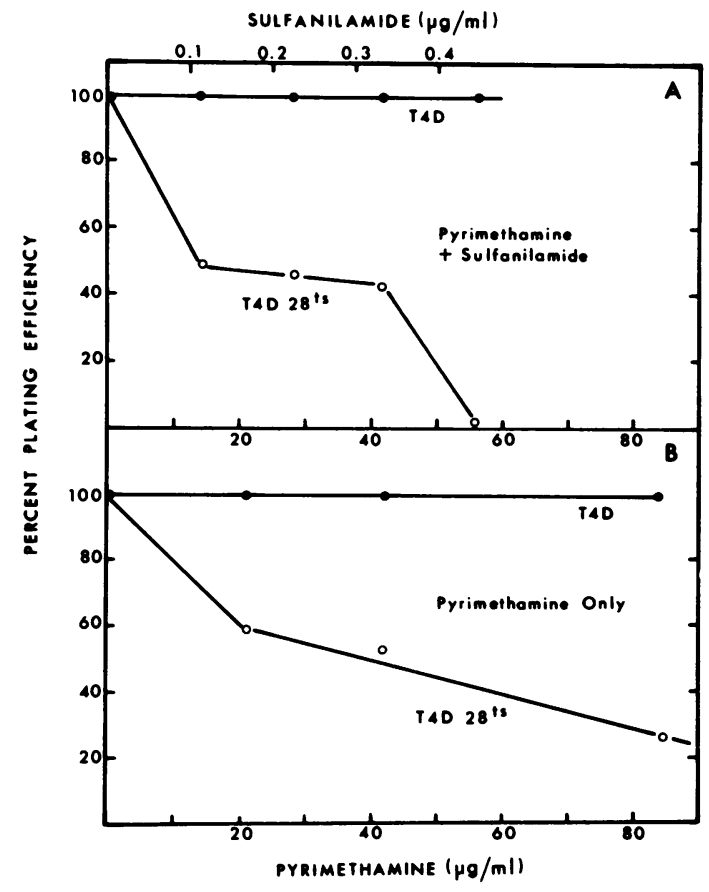

Fig. 2. Effects of pyrimethamine and sulfanilamide on the plating efficiencies of T4D and T4D $28^{\text {ts }}$. (A) Pyrimethamine and sulfanilamide were both added to assay plates containing the medium (containing uracil) used for $E$. coli strain $O K 305$ at the concentrations indicated. The sulfanilamide concentrations are indicated at the top, and the pyrimethamine concentrations are indicated at the bottom. Then samples of either T4D or T4D $28^{\text {ts }}$ were plated onto $E$. coli $O K 305$ in the standard manner, and the plates were incubated overnight at $25^{\circ} \mathrm{C}$. (B) Only pyrimethamine was added to both the base broth layer and the broth overlay tubes. $E$. coli $B$ was the plating bacterium used with these phages, and the plates were incubated overnight at $25^{\circ} \mathrm{C}$.

produced identical reductases, the sensitivity of T4D $28^{\text {ts }}$ suggested that it was the gene 28 product itself which reacted with this folate analog.

Similarly, we examined the effect of $0.3 \mathrm{mM}$ pyrimethamine in broth on the plating efficiencies of T4D am28 and wild-type T4D on two different $E$. coli $\mathrm{K}-12$ hosts. At $37^{\circ} \mathrm{C}$, pyrimethamine lowered the plating efficiency of T4D to 35 to $45 \%$ on $E$. coli $\mathrm{K}-12 \mathrm{Su}^{1+}$ and $\mathrm{Su}^{2+}$, whereas the plating efficiency of T4D am28 was lowered much more (only $3 \%$ of the plating efficiency in the absence of pyrimethamine).

Table 1 shows the effects of sulfadiazine and pyrimethamine on a T4D $28^{\text {ts }}$ revertant. Revertant $a_{1}$ was largely insensitive to the presence of sulfadiazine or pyrimethamine.

Folyl polyglutamate cleavage activity of uninfected $E$. coli B. No true folyl polygluta- 
TABLE 1. Sensitivities of T4D, T4D $28^{t s}$, and a T4D $28^{\text {ts }}$ revertant to various inhibitors

\begin{tabular}{|c|c|c|}
\hline \multirow[b]{2}{*}{ Phage } & \multicolumn{2}{|c|}{ Plating efficiency on: ${ }^{a}$} \\
\hline & $\begin{array}{l}1 \mathrm{mM} \text { sulfadi- } \\
\text { azine }\end{array}$ & $\begin{array}{c}0.25 \mathrm{mM} \text { pyri } \\
\text { methamine }\end{array}$ \\
\hline $\mathrm{T} 4 \mathrm{D}$ & 1.0 & 0.9 \\
\hline $\mathrm{T} 4 \mathrm{D} 28^{\mathrm{ts}}$ & 0.1 & 0.2 \\
\hline T4D $28^{\text {ts }}$ revertant $\mathrm{a}_{1}$ & 0.8 & 0.7 \\
\hline
\end{tabular}

${ }^{a}$ The plating efficiency of each viral strain was defined as 1.0 on $E$. coli B grown on $\mathrm{OK} 305$ medium (5) and incubated at $30^{\circ} \mathrm{C}$. The inhibitors were incorporated into $\mathrm{OK} 305$ medium at the concentrations indicated.

mate cleavage activity has ever been reported in procaryotic cells. However, only recently have the larger polyglutamate forms containing up to seven glutamate residues become available, and even longer chains containing up to 12 to 14 glutamates have become available only through the use of folates isolated from $E$. coli $\mathrm{B}$ infected with T4D $28^{-}$. As indicated above, we developed an assay for cleavage activity by using biologically prepared substrates. An extract was prepared from $100 \mathrm{ml}$ of uninfected $E$. coli B after growth to a concentration of $4 \times 10^{8}$ cells per ml in broth. The cells were concentrated, suspended in buffer, and then sonicated 10 times (30-s each) in the cold with a Branson Sonifier. The extract was clarified and dialyzed against an appropriate buffer (usually $0.02 \mathrm{M}$ phosphate, $\mathrm{pH} 7.0$ to 8.2).

The most unexpected characteristic of the activity from uninfected $E$. coli B cells was that the optimum $\mathrm{pH}$ was quite alkaline (Fig. 3A). In phosphate buffer the optimum $\mathrm{pH}$ was about 8.4, and in Tris buffer the $\mathrm{pH}$ optimum was about 8.5. Under normal assay conditions, when up to $50 \%$ of the substrate was cleaved, the reaction activity was proportional to time of incubation and to the amount of extract added. This bacterial enzyme activity appeared to be reasonably stable; in addition, at least based on its resistance to overnight dialysis against EDTA, it did not require a metal ion as a cofactor. The enzyme was stable during sucrose gradient centrifugation, and upon centrifugation an extract from uninfected cells gave only a single peak of enzyme activity at $\mathrm{pH}$ 8.2. This bacterial folyl polyglutamate cleavage activity sedimented in a sucrose gradient ( 5 to $20 \%$ ) at about the same rate as the bacterial thymidylate synthetase (molecular weight, 56,000 ) and at about twice the rate of the bacterial dihydrofolate reductase (molecular weight, 20,000). The bacterial enzyme could be precipitated by 20 to $60 \%$ saturated ammonium sulfate; when adsorbed on calcium phosphate columns, this enzyme was eluted readily with 0.1 to $0.2 \mathrm{M} \mathrm{KCl}$ in $0.01 \mathrm{M}$ phosphate buffer ( $\mathrm{pH} 7.0$ ).

Folyl polyglutamate cleavage activity in bacteriophage-infected $E$. coli B. We made extracts from $E$. coli B cells infected with T4D and various mutants of $\mathrm{T} 4 \mathrm{D}$ by using standard procedures developed for making enzyme extracts $(13,14)$. Figure 3B shows the effect of $\mathrm{pH}$ on cleavage activity. The $\mathrm{pH}$ activity curves exhibited two maxima, one at less than $\mathrm{pH} 7.0$ and one at more than $\mathrm{pH}$ 8.0. These results suggested that the virus induced the formation of a new more acidic cleavage activity and, thus, the formation of a new enzyme which cleaved folyl polyglutamates. This biphasic $\mathrm{pH}$ activity curve was found in four experiments. Typically, at $\mathrm{pH} 6.0$ (see below) the specific activity per

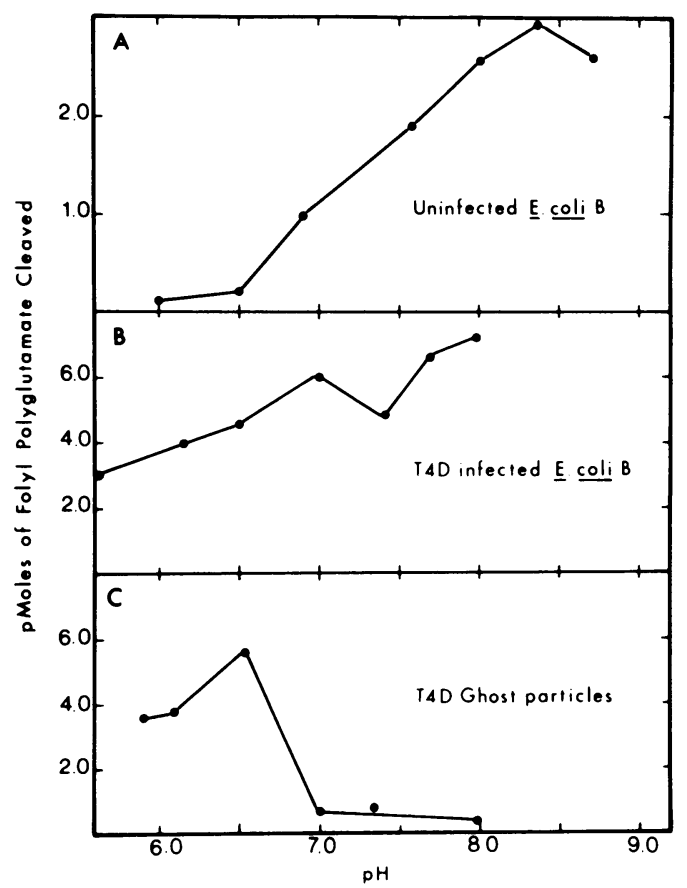

FIG. 3. Effect of $p H$ on folyl polyglutamate cleavage activity in extracts from uninfected $E$. coli $B$ cells $(A)$, extracts from $T 4 D$-infected $E$. coli cells $(B)$, and T4 ghost particles (C). The procedures used are described in the text. Phosphate buffer was present during each reaction at a final concentration of 0.06 $M$. (A) Each reaction mixture contained $8 \mathrm{pmol}$ of total folyl polyglutamate in a volume of $0.075 \mathrm{ml}$ and was incubated for $5 \mathrm{~h}$ at $35^{\circ} \mathrm{C}$ with a $20 \mu \mathrm{g}$ of added protein. (B) Each reaction mixture was incubated at $37^{\circ} \mathrm{C}$ for $4 \mathrm{~h}$ and contained $16 \mathrm{pmol}$ of folyl polyglutamate and $9 \mu \mathrm{g}$ of protein in a final volume of 0.150 $\mathrm{ml}$. (C) Each reaction mixture contained $16 \mathrm{pmol}$ of folyl polyglutamate and $5 \times 10^{11}$ T4D ghost particles in a final volume of $0.15 \mathrm{ml}$. The reaction mixture was incubated for $25 \mathrm{~h}$ at $35^{\circ} \mathrm{C}$. 
milligram of protein of a T4D-infected cell extract was 1.5 to 3.0 times the specific activity of uninfected extracts. Below we show that the new induced folyl polyglutamate cleavage activity was due to an enzyme coded for by T4D gene 28. However, it was possible to characterize and separate the virus-induced enzyme from the host enzyme only partially. These experiments were hampered by the lability of the virus-induced activity. For example, the T4D virus-induced cleavage activity (measured at $\mathrm{pH} 6.0$ ) was labile to ammonium sulfate precipitation and in this respect was quite different from the host enzyme. Furthermore, the virus-induced enzyme bound more firmly to calcium phosphate than the host enzyme and required a higher concentration of $\mathrm{KCl}$ for elution. In sucrose gradients (see below), it had a higher sedimentation rate than the host enzyme. It should be noted that since the molecular weight of gP28 was 24,000 to 25,000 as determined by polyacrylamide gel electrophoresis, the sedimentation behavior suggested that it normally occurs as a polymer or as a complex with some other phage gene product.

Substrate specificity of cleavage activities from uninfected $E$. coli cells and T4Dinfected $E$. coli cells. We examined the sensitivities of two other smaller folyl polyglutamates to the cleavage activity of extracts from uninfected and infected $E$. coli B cells. The final reaction mixtures contained either $1.9 \times 10^{-5} \mathrm{M}$ pteglu $_{3}$ or $3.3 \times 10^{-5} \mathrm{M}$ pteglu 7 ; both of these compounds were labeled in their terminal glutamic acid residues with ${ }^{14} \mathrm{C}$. These substrate concentrations were more than 20 - to 50 -fold higher than the concentration obtained by using the biologically prepared folyl polyglutamate from T4D $28^{-}$-infected cells. When extracts containing protein concentrations comparable to those used in the experiments described in the legend to Fig. 3 were incubated at either $\mathrm{pH} 8.0$ or $\mathrm{pH} 6.5$, no cleavage activity was detected after $4 \mathrm{~h}$ of incubation at $35^{\circ} \mathrm{C}$.

Identification of the phage gene responsible for the production of the new viral cleavage activity. The major candidate for the T4D viral gene responsible for the cleavage activity was gene 28. Previous experiments had been interpreted to indicate that the gene 28 product did play such a role in folate metabolism. When extracts of T4D 28am-infected $E$. coli $\mathrm{B}$ cells were prepared, the $\mathrm{pH}$ activity curve could be superimposed on the $\mathrm{pH}$ activity curve (Fig. 3A) from uninfected cells. Similarly, extracts from $E$. coli B cells infected with T4D $28^{\text {ts }}$ at the high temperature produced no more activity than the host. The lability of the gene 28 product (i.e., the cleavage enzyme) made some experiments difficult. Extracts from cells infected with T4D $28^{\text {ts }}$ prepared at 25 to $27^{\circ} \mathrm{C}$ occasionally had additional induced cleavage activity, but on occasion they had no more activity than host background cleavage activity. Furthermore, extracts from T4D 29am-infected cells produced a $\mathrm{pH}$ activity curve between $\mathrm{pH} 6.0$ and 7.0 that was intermediate between the activity curves produced by extracts from T4D- and from T4D 28am-infected cells. In all cases where ambiguous activities were obtained, extracts were prepared and assayed again. It should be emphasized that T4D 28am and T4D $28^{\text {ts }}$ (prepared at high temperature) extracts never showed cleavage activity above the bacterial background activity, but other results were more variable. In view of the lability of this activity, any increase above the host cleavage activity at pH 6.0 was taken as an indication that these mutants did induce this activity. Extracts were compared only when they were prepared, stored, and assayed at the same time. The following results were obtained for relative cleavage activities (measured as picomoles of folate polyglutamate cleaved per milligram of protein per minute) at $\mathrm{pH}$ 6.0: extracts from wild-type T4Dinfected cells (see above), 1.5 to 3.0 times the host bacterial activity; extracts from T4D am29infected $E$. coli B cells, 1.3 to 1.9 times the bacterial activity; extracts from T4D am26-infected $E$. coli B cells, 1.5 to 3.6 times the bacterial activity; and extracts from T4D am23/27, T4D am51, or T4D am10, 1.3 times the host bacterial activity. The products of T4D genes $29,28,26,51$, and 27 are involved in baseplate tail plug assembly, and the gene 10 product initiates baseplate tail wedge assembly (8-10).

Folyl polyglutamate cleavage activity in phage particles and phage substructures. In view of the evidence that the T4D gene 28 product was a viral structural component exposed on the distal surface of the plug of tail baseplate, we measured the folyl polyglutamate cleavage activity of phage ghost particles. (The phage head was broken, and the DNA was digested to remove any contaminant activities; then the preparation was purified on a $\mathrm{CsCl}-\mathrm{D}_{2} \mathrm{O}$ gradient.) Low, comparable activities were found in both highly purified T4D and T2L ghost preparations. Figure $3 \mathrm{C}$ shows a $\mathrm{pH}$ activity curve for T4D particles; an almost identical curve was obtained with the T2L preparation. The validity of the cleavage assays used to obtain the $\mathrm{pH}$ activity curve for T4D ghosts in Fig. $3 \mathrm{C}$ should be discussed. In this experiment, each reacting mixture contained $16.0 \mathrm{pmol}$ of ${ }^{14} \mathrm{C}$-labeled folyl polyglutamate, which in our counting 
system contained $900 \mathrm{cpm}$ (corrected for a background of $38 \mathrm{cpm}$ ). The nonadsorbable ${ }^{14} \mathrm{C}$ was about $80 \mathrm{cpm}$ (approximately $1.4 \mathrm{pmol}$ ); this amount of nonadsorbable ${ }^{14} \mathrm{C}$ counts did not change even after $25 \mathrm{~h}$ of incubation. At $\mathrm{pH} 6.55$, where maximum cleavage activity occurred, 291

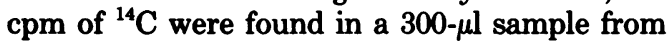
the $400 \mu \mathrm{l}$ in the reaction mixture. Corrected for background (38 cpm), this amounted to 253 or $337 \mathrm{cpm} / 400-\mu \mathrm{l}$ reaction mixture, or a total of 5.9 pmol. Correcting for the $1.4 \mathrm{pmol}$ in the blank gave a net liberation of $4.5 \mathrm{pmol}$. In contrast, at pH 7.7 or 8.0 , the liberated ${ }^{14} \mathrm{C}$ gave 82 to 93 cpm, which was essentially equal to the counts in the trichloroacetic acid blank control.

This enzymatic cleavage activity had a single maximum at about $\mathrm{pH} 6.5$ and was quite different than the host cell cleavage activity. The data in Fig. 3C support the hypothesis that only the new virus-induced gene 28 activity was incorporated into the virus particles. Although the cleavage activity in the phage ghost preparations was only about 2 to $3 \%$ of the activity in the extracts from T4D-infected cells, it was reproducibly measurable in repeated assays of the same preparation, and comparable activities were found in four different phage ghost particle preparations.

The ability of whole phage particles to react with the folyl polyglutamate substrate is in agreement with an exposed location of the gene 28 product. We performed additional experiments to determine the location of this enzymatic activity on the phage particle by using antiserum prepared previously (15) against highly purified T4D phage baseplates. These baseplates were isolated from $E$. coli B cells infected with T4D $54^{-}$and purified by agarose column chromatography and two sucrose density gradient centrifugations; they were free of folic acid (15). Rabbits were immunized with these baseplates and an antiserum (designated B-3) which inactivated live T4D (inactivation rate constant, 300 was obtained). We tested the effect of this anti-tailplate serum on cleavage activity at $\mathrm{pH} 8.2$ with extracts from uninfected $E$. coli $\mathrm{B}$ cells and at $\mathrm{pH} 6.0$ with extracts from T4D-infected $E$. coli B cells. At a final dilution of 1:150, the serum itself had no measurable cleavage activity and also had no effect on the cleavage activity of the bacterial enzyme; $15 \%$ of the substrate was cleaved in the presence or absence of the antiserum. However, at $\mathrm{pH} 6.4$ the serum at this same dilution inhibited the cleavage activity of the extract from T4D-infected cells by more than $90 \%$; in the absence of antiserum $12 \%$ of the substrate was cleaved, whereas in the presence of the antiserum less than $1 \%$ was cleaved. The sensitivity of the virus-induced activity to anti-tailplate serum supported the other evidence concerning the location of this enzymatic activity on the baseplate.

Kikuchi and King (8-10) have described a morphogenetic pathway for the formation of the central plug of the phage tail plate, in which they proposed a sequence of gene product interactions. In this sequence the T4D gene 28 product and gP26 are thought to interact initially with the T4D gene 29 product and form a $7 \mathrm{~S}$ substructure; then a 128 substructure is formed after a reaction with $\mathrm{P}$ 51. This substructure is thought to react with a complex formed between gP27 and gP5 to form the 22S tail plug substructure. We prepared an extract from wild-type T4D-infected $E$. coli B cells and subjected it to sucrose gradient centrifugation. Figure 4 shows the folyl polyglutamate cleavage activity of the fractions collected from the gradient at $\mathrm{pH}$ 6.0. When the preparation was assayed at $\mathrm{pH} 8.2$, the more alkaline host cleavage (data not shown) produced a single sharp peak of activity in fraction 2, compared with the maximal virus-induced activity, which was found in fraction 3. Extracts from T4D am $28^{-}$-infected cells showed no increase in cleavage activity at $\mathrm{pH} 6.0$, and gradients showed a distribution of cleavage activity similar to the distribution from uninfected cells. It is also apparent that the folyl polyglutamate cleavage activity induced by the T4D viral infection was present in a series of components corresponding only roughly to those found by Kikuchi and King (8-10) for tail plug assembly. Although the maximum virus-induced cleavage activity was found in fraction 3 , we observed significant cleavage activity in material

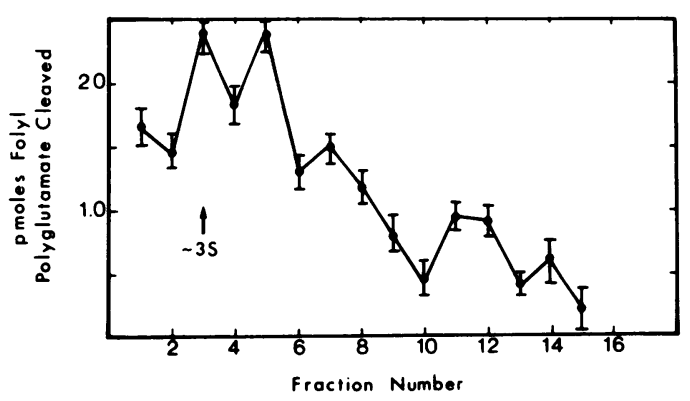

Fig. 4. Sedimentation behavior of the folyl poly. glutamate cleavage activity in an extract from $T 4 D$. infected $E$. coli cells. An extract was prepared in the standard manner from $400 \mathrm{ml}$ of $E$. coli cells infected with T4D. This extract was concentrated in a dialysis bag to $1.0 \mathrm{ml}$ (with Sephadex outside the bag), and this material was layered onto a 29-ml 5 to $20 \%$ sucrose gradient in $0.006 \mathrm{M}$ phosphate buffer ( $\mathrm{pH}$ 7.4). After centrifugation for $30 \mathrm{~h}$ at $24,000 \mathrm{rpm}, 2.0-\mathrm{ml}$ fractions were collected from the top of the gradient and dialyzed against BUM buffer (6-8). The folyl polyglutamate cleavage activity in each fraction was measured at pH 6.0. 
sedimenting at about $5 \mathrm{~S}, 7 \mathrm{~S}$, and 11S. These fractions were assayed for gene 28 product activity by using an in vitro complementation assay. Samples of the fractions were added to an extract from $E$. coli B cells infected with T4D $28^{\text {ts }}$ at $44^{\circ} \mathrm{C}$. At this temperature, the T4D $28^{\text {ts }}$ gene 28 product was denatured, and any wild-type gene 28 product or product complex present in the gradient fractions presumably could complement this T4D $28^{\text {ts }}$ extract. Equal volumes of the dialyzed gradient fractions and the T4D $28^{\text {ts }}$ extract were mixed and incubated overnight at $44^{\circ} \mathrm{C}$. The maximum complementation titer was obtained by using fraction 3 , the tube containing the maximum $\mathrm{pH} 6.0$ cleavage activity. In this case the complementation was four times the titer of the live phage initially present in the extracts. However, this degree of complementation was still quite low, and reliable complementation results were not obtained with other gradient fractions.

Properties of folyl polyglutamate cleavage enzymes induced by T4D and T4D $28^{\text {ts }}$ in $E$. coli $B$ extracts and of the cleavage enzymes in T4D and T4D $28^{\text {ts }}$ particles. A gradient analysis similar to the one described above was performed with an extract from $E$. coli $\mathrm{B}$ cells infected at $27^{\circ} \mathrm{C}$ with T4D $28^{\text {ts }}$. Much less (about one-fifth) cleavage activity was found in these fractions than in the fractions shown in Fig. 4, but the material sedimenting at about $11 \mathrm{~S}$ did have cleavage activity and appeared to be reasonably stable. Since the T4D-induced cleavage activity in fraction 11 from the gradient shown in Fig. 4 and the corresponding T4D $28^{\text {ts }}$ gradient fractions were quite well separated from the host enzyme, we compared them with regard to sensitivity to pyrimethamine. Figure 5 shows the effects of pyrimethamine on the cleavage activities of these fractions containing fast-moving viral substructures from the sucrose gradients. The T4D $28^{\text {ts }}$-induced cleavage activity was very sensitive to pyrimethamine, whereas the T4D-induced enzyme was largely insensitive to this folate analog. These relative sensitivities correlated well with the effects of pyrimethamine on the plating efficiencies of these two viral strains.

Figure 5 also shows the effect of pyrimethamine on the folyl polyglutamate cleavage activities of T4D and T4D $28^{\text {ts }}$ ghost particles. The cleavage activity of T4D $28^{\text {ts }}$ ghosts was sensitive to pyrimethamine, whereas the activity of T4D particles was largely unaffected by pyrimethamine. Since a single mutation in T4D gene 28 alters the properties of an enzymatic activity in the viral particle, we concluded that this enzyme must be coded for by this gene.

Cleavage activity in various phage preparations and the locus of the enzyme on the

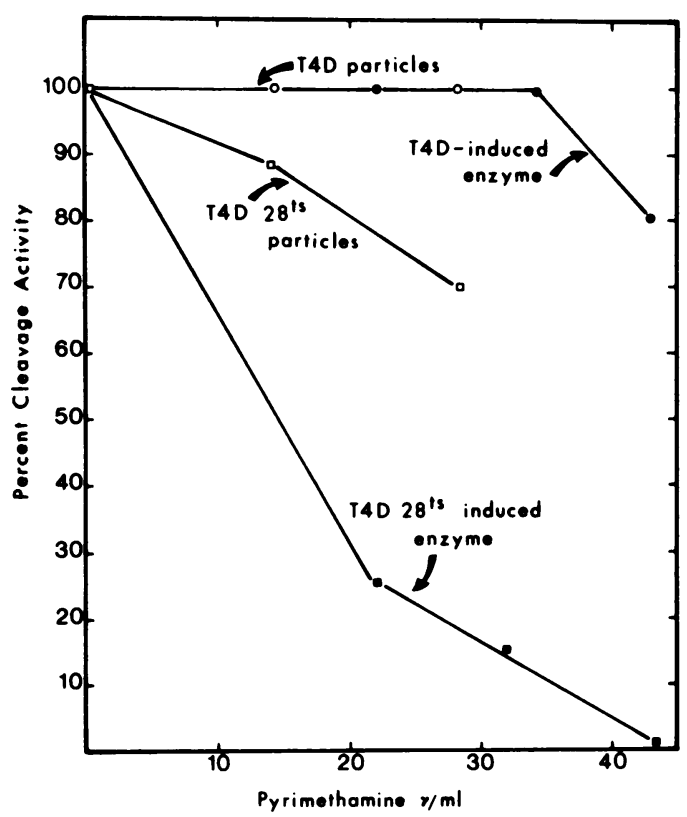

Fic. 5. Effects of pyrimethamine on the folyl polyglutamate cleavage activities of T4D and T4D $28^{\text {ts }}$ ghost particles and on the cleavage activities of enzymes induced by phage infection. The activities of infected bacterial extracts and of phage particles were measured at $p H$ 6.0. The extracts were from sucrose gradients (see Fig. 4, fraction 11) and were incubated for $6 \mathrm{~h}$; the ghost particles were incubated for 20 h. Symbols: 0 , extract activity for the T4D. induced enzyme; $\mathrm{L}$ extract activity for T4D $28^{\mathrm{s}}$-induced enzyme. The activities of T4D ghost particles (O) and T4D $28^{\text {ss }}$ ghost particles $(\square)$ were measured as described in the legend to Fig. 3.

phage tail. One additional feature of the cleavage activity of the T4D $28^{\text {ts }}$ ghost preparation described above was observed. Compared with T4D ghosts, the T4D $28^{\text {ts }}$ ghost preparation had $20 \%$ of the cleavage activity. However, when examined by electron microscopy, it was apparent that the T4D $28^{\text {ts }}$ preparation contained many free heads and relatively fewer intact ghosts or even free tails compared with the largely intact ghost particles found in the T4D ghost preparation. A direct count of the T4D $28^{\text {ts }}$ ghost preparation showed that there were only 60 tail structures per 268 head structures. Since the head structures contained most of the viral proteins, if the $20 \%$ relative activity (compared with T4D) was multiplied by $268 / 60$, the relative activity per tail of a T4D $28^{\text {ts }}$ particle was about $89 \%$ of the activity of a T4D particle. This observation supported the conclusion that it is the tail structure which is the locus of this enzyme, but it did not locate the enzyme within the tail structure.

The cleavage activity of one additional phage ghost preparation was measured. T4D incom- 
plete ghost particles $\left(11^{-} / 34^{-}\right)$were prepared as described above. These particles lacked both the long tail fibers and the gene 11 and gene 12 baseplate components. These incomplete particles were of interest since the phage baseplate folyl polyglutamate $(14,15)$, dihydrofolate reductase $(14,16)$, and thymidylate synthetase (16) are all exposed more on these incomplete baseplates than on intact baseplates. We found that these $11^{-} / 34^{-}$incomplete particles had cleavage activities equal to the activities of intact T4D ghost particles, T4D $28^{\text {ts }}$ ghost particles (corrected as described above), or T2L ghost particles. This finding with $11^{-} / 34^{-}$particles was in accord with the fact that the baseplate cleavage enzyme was not associated directly with these particular baseplate components mentioned above, which appeared to be located near the apices of the hexagonal baseplate, but was located in the plug portion of the baseplate.

\section{DISCUSSION}

The nature of the cleavage activities in extracts from uninfected cells, infected cells, and phage particles and substructures deserves comment. It seems very likely that the virus-induced activity is a genuine folyl polyglutamate $\gamma$-glutamate cleavage enzyme. The inhibition of the viral enzyme, either in extracts from cells or in virus particles, by pyrimethamine (an analog of the folate pteridine ring) shows that the active site does recognize this folate component. Furthermore, the lack of activity of the viral enzyme against the tri- and heptaglutamate derivatives shows a considerable specificity for a large number of glutamate residues. Although the cleavage activity in uninfected cells differs from that in infected cells, the nature of this bacterial enzyme is less certain. Based on the absence of cleavage activity when the triglutamate or the hepatglutamate derivatives were used as substrates, it is unlikely that the bacterial enzyme attacks some bond other than a $\gamma$-glutamyl peptide bond. Given that the bacterial enzyme is a $\gamma$-glutamyl hydrolase (probably an endopeptidase) for a high-molecular-weight compound, it still must be shown that the pteridine moiety is a required part of the substrate.

The results described here and in the accompanying paper clearly show that the product of T4D gene 28 plays an unexpected dual role in phage reproduction. This dual role is illustrated in Fig. 6. It has been shown previously $(12,20)$ that in cells infected with phage unable to form the gene 28 product an unusual folate polyglutamate containing 12 to 14 glutamate residues accumulates. The gene 28 product was thought to function as a cleavage enzyme and our results clearly show that the gene 28 product is such a cleavage enzyme. Work is currently in progress to determine the chemical nature of the cleavage products and the substrate specificity of this virus-induced enzyme, as well as the enzymatic nature of the activity found in uninfected bacterial cells. Additional experiments might also offer some explanation of why the host cleavage enzyme cannot form enough of the phage-specific pteroyl hexaglutamate or cleave the large folyl polyglutamates in T4D 28am-infected cells to allow tail assembly.

It should be emphasized (Fig. 6) that other, as-yet-unidentified phage genes are involved in the biosynthesis of the phage pteroyl hexaglutamate. For instance, it has been shown that phage infections cause the formation of increased amounts of pteroyl hexaglutamate (17,

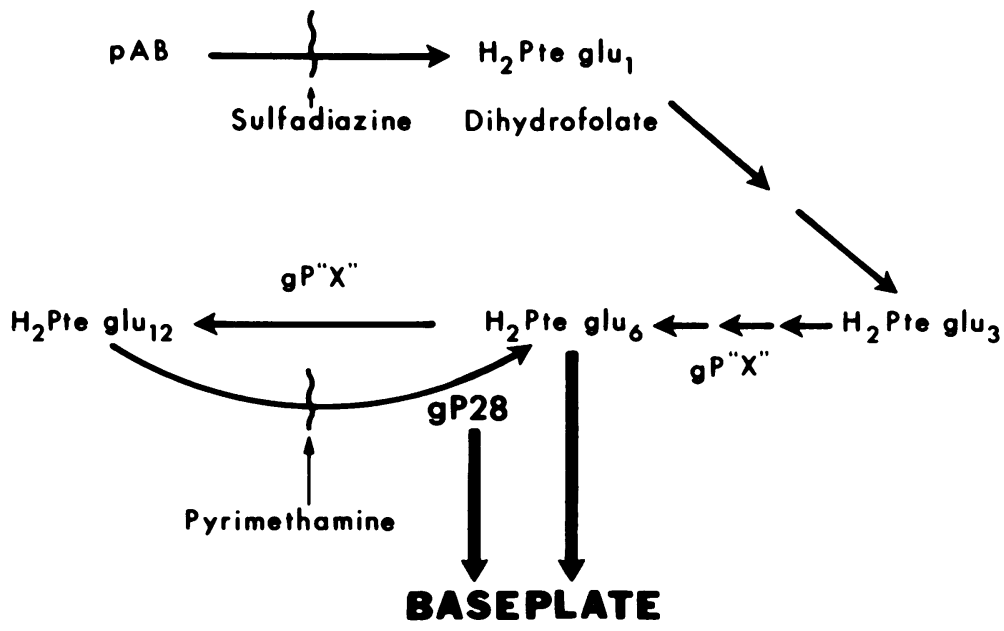

Fig. 6. Folyl polyglutamate metabolism and baseplate assembly in T4D-infected E. coli B cells. 
20) and larger folyl polyglutamates. This increased synthesis is obviously due to the action of one or more phage gene products. This role of an unidentified phage gene(s) is indicated by the proposed role of "gPX."

Figure 6 also shows the effects of sulfa drugs in inhibiting plaque formation by T4D $28^{\text {ts }}$ and T4D am28. In cells infected with phage mutants in gene 28 , the gene 28 product is less effective than the enzyme induced by wild-type T4D. This lowered efficiency means a greater sensitivity to a reduced level of folate synthesis. In effect, in the presence of sulfa drugs in a T4D $28^{\text {ts }}$ - or T4D $28 \mathrm{am}$-infected cell, there is a decreased rate of synthesis of the pteroyl hexa compound. Similarly, treatment with primethamine plus a sulfa drug produces a marked sequential inhibition of the formation of a phage folate compound in T4D $28^{\text {ts }}$-infected cells, which inhibits phage formation.

Evidence that the virus-induced gene 28 protein is a necessary component of the tail plug of the baseplate is presented here and in the accompanying paper (17). The action of pyrimethamine should be emphasized. This compound inhibits the enzymatic cleavage activity of T4D $28^{\text {ts }}$ particles but not the activity of T4D particles. This result can be interpreted as due to pyrimethamine binding to the exposed active site on the gene 28 product on the distal surface of the baseplate. This interpretation of the effect of pyrimethamine on this property is in agreement with similar conclusions based on the use of antisera to tailplates or on changes in adsorption rates, host ranges, and injection efficiencies with changes in the gene 28 product.

A dual catalytic and structural function for the product of T4D gene 28 has several precedents since at least three other tail baseplate structural components also have catalytic functions. Recently, Meade et al. (19) showed that dihydrofolate reductase, a virus-induced enzyme and a structural component of the baseplate (14, 16 ), is a component of baseplate wedges. In the accompanying paper (17) Kozloff and Zorzopulos present the first analytical evidence that the virus-induced thymidylate synthetase (also known to be in the baseplate) is actually a component of the central tail plug. Finally, Kao and McLain $(6,7)$ have presented evidence that the gP5 of the central plug has lytic activity on the host cell. In summary, three of the six structural components of the central plug (gP28, gP5, and gPtd [thymidylate synthetase]) are known or presumed to have catalytic activities and, in addition, another enzyme (dihydrofolate reductase) is a component of the baseplate wedges. These multiple functions must be considered in schemes describing the assembly and function of this viral substructure.

\section{ACKNOWLEDGMENTS}

This research was supported by Public Health Service research grant AI 06336 from the National Institute of Allergy and Infectious Diseases.

We are grateful to C. M. Baugh for the gifts of ${ }^{14} \mathrm{C}$-labeled labile folate molecules containing three glutamate residues and seven glutamate residues and to J. Burchall, Burroughs Wellcome Co., for the samples of pyrimethamine and trimethoprim.

\section{LITERATURE CITED}

1. Adams, M. H. 1959. Bacteriophages. Interscience Publishers, Inc., New York.

2. Allfrey, V., L. J. Tepley, C. Geffen, and C. G. King. 1949. A fluorometric method for the determination of pteroylglutamic acid. J. Biol. Chem. 178:465-481.

3. Baugh, C. M., E. Braverman, and M. G. Nair. 1974. The identification of poly- $\gamma$-glutamyl chain lengths in bacterial folates. Biochemistry 13:4952-4957.

4. Baugh, C. M., and C. L. Krumdieck. 1971. Naturally occurring folates. Ann. N.Y. Acad. Sci. 186:7-28.

5. Johnson, J. R., and D. H. Hall. 1972. Isolation and characterization of bacteriophage T4 resistant to folate analogues. Virology 53:413-426.

6. Kao, S. H., and W. H. McLain. 1980. Baseplate protein of bacteriophage T4 with both structural and lytic functions. J. Virol. 34:95-103.

7. Kao, S. H., and W. H. McLain. 1980. Roles of T4 gene 5 and gene $S$ in cell lysis. J. Virol. 34:104-107.

8. Kikuchi, Y., and J. King. 1975. Genetic control of bacteriophage T4 baseplate morphogenesis. I. Sequential assembly of the major precursor in vivo and in vitro. J. Mol. Biol. 99:645-672.

9. Kikuchi, Y., and J. King. 1975. Genetic control of bacteriophage T4 baseplate morphogenesis. II. Mutants unable to form the central part of the baseplate. J. Mol. Biol. 99:673-694.

10. Kikuchi, Y., and J. King. 1975. Genetic control of bacteriophage T4 baseplate morphogenesis. III. Formation of the central plug and overall assembly pathway. J. Mol. Biol. 99:695-716.

11. Kozloff, L. M., and M. Lute. 1965. Folic acid, a structural component of T4 bacteriophage. J. Mol. Biol. 12:780792.

12. Kozloff, L. M., and M. Lute. 1973. Bacteriophage tail components. IV. Pteroyl polyglutamate synthesis in T4D-infected Escherichia coli B. J. Virol. 11:630-636.

13. Kozloff, L. M., M. Lute, and C. Baugh. 1973. Bacteriophage tail components. V. Complementation of T4D gene 28-infected bacterial extracts with pteroyl hexaglutamate. J. Virol. 11:637-641.

14. Kozloff, L. M., M. Lute, and L. K. Crosby. 1977. Bacteriophage T4 virion baseplate thymidylate synthetase and dihydrofolate reductase. J. Virol. 23:637-644.

15. Kozloff, L. M., M. Lute, L. K. Crosby, N. Rao, V. A. Chapman, and S. S. DeLong. 1970. Bacteriophage tail components. I. Pteroyl polyglutamates in T-even bacteriophages. J. Virol. 5:726-739.

16. Kozloff, L. M., C. Verses, M. Lute, and L. K. Crosby. 1970. Bacteriophage tail components. II. Dihydrofolate reductase in T4D bacteriphage. J. Virol. 5:740-753.

17. Kozloff, L. M., and J. Zorzopulos. 1981. Dual functions of bacteriophage T4D gene 28 product: structural component of the viral tail baseplate central plug and cleavage enzyme for folyl polyglutamates. I. Identification of T4D gene 28 product in the tail plug. J. Virol. 40:635644.

18. Krumdieck, C. L., and C. M. Baugh. 1970. Radioactive assay of folic acid polyglutamate conjugase(s). Anal. Biochem. 35:123-129.

19. Meade, L. C., A. A. Direnzo, R. K. Bestwick, R. A. Mosher, and C. K. Mathews. 1979. Molecular cloning of T4 phage genes controlling folate metabolism, p. 321326. In R. L. Kisliuk and G. M. Brown (ed.), Chemistry 
and biology of pteridines. Developments in biochemistry, vol. 4. Elsevier/North-Holland Publishing Co., New York.

20. Nakamura, K., and L. M. Kozloff. 1978. Folate polyglutamates in T4D bacteriophage and T4D-infected Escherichia coli. Biochim. Biophys. Acta 540:313-319.

21. Silink, M., R. Redde, M. Bethel, and P. B. Rowe. 1975.
$\gamma$-Glutamyl hydrolase (conjugase) purification and properties of the bovine enzyme. J. Biol. Chem. 250: 5982-5994.

22. Volcani, B. E., and P. Margolith. 1957. A new species (Flavobacterium polyglutamicum) which hydrolyses the $\gamma$-L-glutamyl bond in polypeptides. J. Bacteriol. 70: 646-655. 